\title{
Agency, Time and Urban Transformation
}

\author{
Mahyar Arefi ${ }^{1} \cdot$ Noha Nasser $^{2}$
}

Published online: 6 November 2019

(c) Springer Nature Limited 2019

This issue of Urban Design International focuses on the interplay between agency, time, and positive urban change. Contemporary buzzwords including placelessness, loss of local identity, transient urbanism, resiliency, sustainability, and everyday urbanism, among other things, bring to mind the impact of time on spatial and social transformation. For example, Relph's (1976) notion of placelessness carries with it not just the interface between physical change and the loss of local identity, but also the time it takes to experience them. Transient, DIY (Do It Yourself), Guerrilla urbanism, on the other hand, makes note of rapid changes certain public and urban spaces undergo. Regardless of the roles of various groups of citizens and other stakeholders as agents of change, time plays important roles in all of them. Other time-honored concepts including resiliency, sustainability, or climate change matter to urban designers not just because they examine important challenges our cities are currently facing, but also the amount of time necessary to curbing or facilitating them.

These terminologies and many more attest to a sense of urgency urban planning and design scholars and professionals have been expressing over the last decades or so. This issue of UDI explores a few of these concepts that have gained traction among urban design scholars and practitioners. The first article by Atmodiwirjo, Johanes \& Andri Yatmo focuses on urban mapping, which evokes the essence of everyday urbanism approaches to local design and planning. Social media and VGI (Voluntary Geographical Information) play important roles in creating and disseminating local narratives. This type of mapping operates as a medium that interfaces the urban space-actors' relationships, and rather than viewing the public space as a closed, rigid system, it treats it as an open-ended, dynamic, interactive, performative, pluralistic, and collectively shaped space.

Mahyar Arefi

mahyararefi@gmail.com

University of Texas at Arlington, Arlington, USA

2 Cardiff University, Cardiff, UK
Performances in this broad context signify re-appropriation of space by ways of "doing things" (de Certeau 1984).

However, re-appropriation of public space does not necessarily happen in short periods of time traceable in everyday practices, and, as Carmona notes, may occur during the times of austerity, i.e., in decades. Using four European case studies of London, Malmo, Copenhagen, and Oslo, Carmona provides a broad array of transformations these cities underwent from austerity (read management) to advocacy. Gleaning lessons from each case study, the author shows how new narratives have emerged from such experiences in these socio-democratic settings. Spaces of spectacle, spaces of decline, spaces of expectation, spaces of respite, spaces of community control, spaces of income generation, spaces of infrastructure, spaces of security, spaces of occupation, and spaces of the ephemeral city exemplify some of these variations during the times of economic austerity. These variations on a theme remind us that even in times of austerity, physical or social change need not portend signs of economic hardship but sings of adaptation and shifting from 'place-making' to 'place-shaping'.

The third type of transformation focuses on the concept of "formats," which also places partial emphasis on the transformation of urban spatial structures that often encompass different urban districts. Based on this usage and using a case study in People's Square and Shanghai's Lujiazui District, Yang argues that "formats" have multiple themes such as locations (i.e., the concentration of business offices). However, the growth of these financial businesses justifies supplemental types of services and spaces, i.e., financial insurance firms and their respective growth through the law of supply and demand. Finally, these developments, in turn, result in the formation of other services including transportation and administrative demands and concentrations, along with their negative externalities, i.e., noise and other environmental pollutions and diseconomies.

The next contribution explores urban change within the concept of Indigenous participation in Christchurch, New Zealand. Moving away from the colonial legacy of a limited role in local participation, Thompson-Fawcett, Kitson, and 
Barry explore a new era of inclusionary design when the indigenous population exercise agency as active participants in creating public space. Similar to giving a positive spin on the difficult times of austerity, the indigenous population in Christchurch pursued their self-determination by creating new opportunities in the post-earthquake recovery period, and acted as urban developers rather than passive users.

The fifth and last article by Kim explores the time, agency, and urban transformation nexus against the backdrop of public space eateries in London. While not explicitly stated, time and change play important roles in the stakeholders' interactions in public space. Observing and analyzing the social network in two London public spaces reveals dynamic interactions among builders, instruments, and spokesmen, each of whom assuming their agency roles within certain time frames. Instruments, for example, include continuous relations among the actors from the local market to office blocks and the broader physical context. Builders, however, connote the local Kingston Borough Council's continuous involvement in the transformation of public space. Of course, as agents, users of public space also remain actively involved as part of this complex network in using the eateries. These examples certainly add new contributions to the urban design literature.

\section{References}

de Certeau, Michel. 1984. The Practice of Everyday Life. Beverly, CA: University of California Press.

Relph, Edward. 1976. Place \& Placelessness. London: Pion.

Publisher's Note Springer Nature remains neutral with regard to jurisdictional claims in published maps and institutional affiliations. 